Article

\title{
HPLC Method Development for Quantification of Doxorubicin in Cell Culture and Placental Perfusion Media
}

\author{
Mansi Shah ${ }^{1}$ (D), Luke Bourner ${ }^{2}$, Shariq Ali ${ }^{2,3}$, Sanaalarab Al-Enazy ${ }^{2}$, Menatallah M. Youssef ${ }^{4}$, \\ Morgan Fisler ${ }^{5}$ and Erik Rytting ${ }^{1,2, *}$ \\ 1 Department of Obstetrics \& Gynecology, University of Texas Medical Branch, 301 University Boulevard, \\ Galveston, TX 77555-1062, USA; manshah@utmb.edu \\ 2 Department of Pharmacology and Toxicology, University of Texas Medical Branch, \\ Galveston, TX 77555-1062, USA; labourne@utmb.edu (L.B.); sh2ali@utmb.edu (S.A.); \\ saalenaz@utmb.edu (S.A.-E.) \\ 3 School of Medicine, University of Texas Medical Branch, Galveston, TX 77555-1062, USA \\ 4 Department of Pharmaceutical Analytical Chemistry, Ain-Shams University, Cairo 1156, Egypt; \\ mennamagdy@pharma.asu.edu.eg \\ 5 Department of Obstetrics \& Gynecology, Medical University of South Carolina, \\ Charleston, SC 29425-2221, USA; fisler@musc.edu \\ * Correspondence: erik.rytting@utmb.edu
}

Received: 20 November 2017; Accepted: 10 January 2018; Published: 24 January 2018

\begin{abstract}
Assessment of drug transport across the placenta is important in understanding the effect of drugs on placental and fetal health. These phenomena can be studied in both in vitro cell lines and ex vivo placental perfusions. We have successfully developed a sensitive yet simple high performance liquid chromatography (HPLC) method coupled with fluorescence detection to determine the concentration of doxorubicin (DXR) in cell culture media for transport studies in human trophoblast cells (BeWo, b30 clone) and in fetal media for placental perfusion experiments. The method was developed based on a protein precipitation technique and was validated in both media types for linearity, intra-day, and inter-day precision and accuracy. The relationship of peak area to concentration was linear with $R^{2}$ values of 0.99 or greater obtained over the concentration range of 1.5 to $15,000 \mathrm{ng} / \mathrm{mL}$. Despite the high concentrations of albumin in fetal perfusion media (30 mg/mL), the lower limits of detection and quantification for DXR were found to be 1.5 and $5 \mathrm{ng} / \mathrm{mL}$, respectively. This analytical method may be used to study the transport of DXR across BeWo cells and human placenta during placental perfusion studies.
\end{abstract}

Keywords: doxorubicin; BeWo cell culture media; placenta; high performance liquid chromatography; fluorescence; anthracycline; analytical method; perfusion

\section{Introduction}

The occurrence of breast cancer in pregnant women has increased over the past few years, complicating approximately 1 in 3000 pregnancies. Moreover, treatment strategies involving chemotherapy can be toxic to the fetus [1]. Pregnancy is a dynamic state in which the body undergoes several anatomical and physiological changes. These changes can alter the pharmacokinetics and pharmacodynamics of the drug compared to non-pregnant subjects [2]. However, pharmacokinetic studies have rarely been performed on pregnant women receiving chemotherapy. Doxorubicin is commonly prescribed during pregnancy for the treatment of malignancies such as breast cancer, ovarian cancer, and solid tumors [3], despite the fact that the FDA has defined it as pregnancy category D (positive evidence of 
risk). Therefore, it is imperative to study the transplacental transfer of the drug itself and its liposomal formulation (Doxil ${ }^{\circledR}$ ) and understand its implications on fetal development.

Doxorubicin (DXR) is an anthracycline antibiotic isolated from the bacterium Streptomyces peucetius var. caesius and is available as a hydrochloride salt. Doxorubicin has multiple mechanisms of action, including DNA intercalation and prevention of transcription, inhibition of topoisomerase II, and induction of cytotoxicity by the formation of oxygen free radicals [4]. DXR is known to be rapidly and extensively distributed to various organs such as the heart, liver, kidney, and spleen, but little is known about its transport and accumulation in the placenta [4-6]. Therefore, to investigate the mechanisms involved in the transplacental transfer of doxorubicin, various in vitro and ex vivo models can be studied [7]. The BeWo (b30 clone) cell line, which is a model of the human placental trophoblast, and the dually perfused human placental lobule are both widely used in vitro and ex vivo models to study the transplacental transfer of various drugs and their metabolites [7,8]. In order to study the transplacental transport of DXR across BeWo cells and placenta during placental perfusion studies, it is necessary to have simple, selective, and validated high performance liquid chromatography (HPLC) methods for determining DXR concentrations in media.

A handful of analytical methods for the determination of doxorubicin in biological fluids are available; however, to the best of our knowledge, none have been published for quantification in DMEM/F12 cell culture media and/or placental perfusion media. Some of the methods involve sample preparations such as liquid-liquid extraction [9-12] or solid phase extraction [13], which can be tedious and require the use of an internal standard. Other methods with protein precipitation involved the use of perchloric acid [14], which can cause deterioration of both the analyte and typical silica-based reversed-phase HPLC columns. While screening materials to use as a protein precipitant, we observed instability in DXR in the presence of perchloric acid. Other methods involve mass spectrometry, which may be highly sensitive but cost-prohibitive for many laboratories [15]. If the drug of interest is inherently fluorescent, fluorescence detection is often preferable because it is simple, inexpensive, and more sensitive in comparison to ultraviolet absorption. A recent method based upon protein precipitation was used to determine doxorubicin in arthritic joints, but it has a lower limit of quantification of only $0.8 \mu \mathrm{g} / \mathrm{mL}$ [16]. Therefore, even though several methods have been used to detect DXR in biological fluids, there is great benefit to developing a simple method with a low limit of quantification $(5 \mathrm{ng} / \mathrm{mL}$ ) for the assessment of DXR in cell culture and placental perfusion media.

For these reasons, we have developed a sensitive reversed-phase HPLC method using fluorescence detection for the quantification of DXR in DMEM/F12 cell culture medium and M199 placental perfusion medium containing $30 \mathrm{mg} / \mathrm{mL}$ human serum albumin. Since DXR exhibits high protein binding (45-85\%), it is very important to use the physiological concentration of albumin, which can affect the transplacental transport of DXR $[17,18]$. Method development in placental perfusion medium is particularly challenging due to this high concentration of albumin. The method developed was reliable and highly sensitive. We believe that the simplicity of the sample preparation method and the portability between the two different types of media makes this an accessible and valuable method for laboratories studying doxorubicin's interactions with the placenta.

\section{Materials and Methods}

\subsection{Chemicals and Reagents}

Doxorubicin hydrochloride was obtained from Oakwood Chemical (Estill, SC, USA). Cell culture medium for the BeWo b30 cell line contains Dulbecco's Modified Eagle's Medium/Ham's F-12 50/50 mixture without phenol red (Mediatech, Manassas, VA, USA) with $10 \%$ fetal bovine serum (Atlanta Biologicals, Flowery Branch, GA, USA), antibiotic/antimycotic containing 10,000 units/mL penicillin, $10,000 \mu \mathrm{g} / \mathrm{mL}$ streptomycin, and $25 \mu \mathrm{g} / \mathrm{mL}$ amphotericin B (Gibco ${ }^{\circledR}$, Carlsbad, CA, USA), 100X MEM nonessential amino acid solution (Sigma, St. Louis, MO, USA), and $200 \mathrm{mM}$ L-glutamine (Mediatech, Manassas, VA, USA). Placental perfusion medium was prepared using dextran (Sigma 
Aldrich, St. Louis, MO, USA), human serum albumin fraction V (Calbiochem, La Jolla, CA, USA), and medium 199 (Sigma Aldrich). Acetonitrile of HPLC grade, acetone, monobasic potassium phosphate, and phosphoric acid were obtained from Fisher Scientific (Fair Lawn, NJ, USA). Deionized water was obtained from a Millipore Synergy UV Ultrapure Water System (Millipore, Billerica, MA, USA).

\subsection{Chromatographic Instruments and Conditions}

The HPLC system (Waters, Milford, MA, USA) was comprised of a Waters 1525 Binary HPLC pump, a Waters 2707 Autosampler, and a Waters 2475 multi $\lambda$ fluorescence detector. For both methods, a C-18 column $(150 \mathrm{~mm} \times 4.6 \mathrm{~mm}, 5 \mu \mathrm{m}$ particle size, and $100 \AA$ pore size, AkzoNobel/Kromasil, Brewster, NY, USA) was used at ambient temperature.

The mobile phase consisted of an aqueous phase (A) containing $20 \mathrm{mM} \mathrm{KH}_{2} \mathrm{PO}_{4}$ and $0.1 \%(v / v)$ phosphoric acid and an organic phase (B), which was acetonitrile. Flow was set at $1.0 \mathrm{~mL} / \mathrm{min}$. A gradient method was used in which the mobile phase started as $75 \% \mathrm{~A}$ and $25 \% \mathrm{~B}$ and changed in a linear manner to $60 \% \mathrm{~A}$ and $40 \% \mathrm{~B}$ by $7 \mathrm{~min}$. Between 7 and $10 \mathrm{~min}$, the mobile phase ratio was held constant. The mobile phase then reverted to $75 \% \mathrm{~A}$ and $25 \% \mathrm{~B}$ by $12 \mathrm{~min}$ and was held constant to baseline until $15 \mathrm{~min}$. A wash vial containing initial mobile phase was injected between samples to avoid sample carryover. Peaks were monitored using fluorescence detection at an excitation wavelength of $480 \mathrm{~nm}$ and an emission wavelength of $550 \mathrm{~nm}$ using the fluorescence detector.

\subsection{Sample Preparation}

Cell culture medium for the analytical method validation of DXR was prepared as per the protocol in which BeWo b30 cells are typically grown [7]. In brief, cell culture media containing Dulbecco's Modified Eagle's Medium/Ham's F-12 50/50 mixture without phenol red (Mediatech, Manassas, VA, USA) containing 10\% fetal bovine serum (Atlanta Biologicals, Flowery Branch, GA, USA), antibiotic/antimycotic containing 10,000 units/mL penicillin, 10,000 $\mu \mathrm{g} / \mathrm{mL}$ streptomycin, and $25 \mu \mathrm{g} / \mathrm{mL}$ amphotericin B (Gibco ${ }^{\circledR}$, Life Technologies, Carlsbad, CA, USA), 100X MEM nonessential amino acid solution (Sigma, St. Louis, MO, USA) and $200 \mathrm{mM}$ L-glutamine (Mediatech, Manassas, VA, USA) was prepared and stored at $4{ }^{\circ} \mathrm{C}$ until further use.

For the analytical method validation of DXR in placental perfusion medium, fetal perfusion media was used. Here, we have selected only fetal perfusion medium as the only difference between maternal and fetal perfusion media is the level of dextran. Maternal perfusion medium contains $3.0 \mathrm{mg} / \mathrm{mL}$, whereas fetal perfusion medium contains $12.0 \mathrm{mg} / \mathrm{mL}$ dextran. Fetal perfusion medium was prepared using deionized water in which solid medium 199 with Earle's salts $(11 \mathrm{mg} / \mathrm{mL})$, dextran $(12 \mathrm{mg} / \mathrm{mL})$, heparin $(29 \mu \mathrm{g} / \mathrm{mL})$, gentamicin $(33.3 \mu \mathrm{g} / \mathrm{mL})$, sulfamethoxazole $(80 \mu \mathrm{g} / \mathrm{mL})$, trimethoprim $(16 \mu \mathrm{g} / \mathrm{mL})$, and human serum albumin $(30 \mathrm{mg} / \mathrm{mL})$ were dissolved and the $\mathrm{pH}$ of the media was adjusted to 7.4 using sodium bicarbonate [18]. All of the above mentioned chemicals used in fetal perfusion media were obtained from Sigma Aldrich (St. Louis, MO, USA). The prepared perfusion medium was stored at $4{ }^{\circ} \mathrm{C}$ and was used within a week.

A stock solution of $300 \mu \mathrm{g} / \mathrm{mL}$ of doxorubicin hydrochloride was prepared in purified water. Using this stock solution, $15 \mu \mathrm{g} / \mathrm{mL}$ DXR hydrochloride in cell culture media (DMEM/F12, phenol red free) was prepared. The series of dilutions were prepared in cell culture media. Thereafter, in order to remove the proteins, samples for HPLC analysis were prepared by a protein precipitation technique. Briefly, in a microcentrifuge tube, $250 \mu \mathrm{L}$ of media samples with known concentrations of doxorubicin were added to $1.0 \mathrm{~mL}$ of acetone (1:4 ratio). Samples were then centrifuged at $16,100 \times \mathrm{g}$ for $20 \mathrm{~min}$ to pellet the precipitated proteins. At the end of the centrifugation, $1.0 \mathrm{~mL}$ of supernatant was collected in a glass vial and allowed to evaporate in a vacuum oven (Napco Model No. 5831, Napco, Tualatin, OR, USA) using a chemical resistant pump (Labnet, Model No. D4000, Labnet, Edison, NJ, USA) for $30 \mathrm{~min}$, followed by drying under a nitrogen stream (ZipVap 24, Glas-Col, Terre Haute, IN, USA) until complete dryness. Once dried, $100 \mu \mathrm{L}$ of initial mobile phase $(75 \%$ aqueous phase and $25 \%$ organic phase) was used to reconstitute the residual content, and the sample was transferred to 
an HPLC vial containing an insert, and $50 \mu \mathrm{L}$ was injected into the HPLC system using partial loop with needle overfill.

\subsection{Transplacental Transfer of DXR across BeWo Cells and the Dually Perfused Human Placental Lobule}

To further confirm the validity and suitability of our validated HPLC method, a short experiment in the presence of BeWo cells and a placental perfusion of DXR was performed. For transport across the BeWo cells, a method was followed as per a previous report [19], and sample was collected from the basolateral chamber at $30 \mathrm{~min}$. In the case of placental perfusion, a published method was followed with slight modification [20]. In brief, a placenta from an uncomplicated pregnancy at the John Sealy Hospital Labor and Delivery unit was immediately collected. After thorough evaluation, one placental lobule was selected, and a fetal artery and vein were catheterized. The maternal side of the placenta was perfused at a flow rate of $12.0 \mathrm{~mL} / \mathrm{min}$, whereas the fetal side was perfused at $3 \mathrm{~mL} / \mathrm{min}$. After addition of doxorubicin into the material reservoir, $1.0 \mathrm{~mL}$ of sample was withdrawn at $30 \mathrm{~min}$ from the fetal reservoir and analyzed by HPLC for doxorubicin determination to check the suitability of the HPLC method. Care was taken to supply 95\% nitrogen and 5\% carbon dioxide to the fetal reservoir and $95 \%$ oxygen and $5 \%$ carbon dioxide to the maternal reservoir $(250 \mathrm{~mL})$ to ensure acceptable oxygen transfer and placental viability.

\subsection{Assay Validation}

\subsubsection{Linearity, Precision, and Accuracy}

The calibration curve was prepared using the peak areas obtained from the chromatograms. Linear regressions were made using SigmaPlot (version 13.0) based on $1 / y$ weighting to minimize the sum of squares of relative errors across the concentration range $(1.5-15,000 \mathrm{ng} / \mathrm{mL})$. In order to calculate various parameters including intra-day precision, inter-day precision, and accuracy, ICH guidance for method validation of analytical procedures was followed [21]. Intra-day precision was calculated based upon relative standard deviation (\%RSD) of the peak area from three concentrations (6 determinations per concentration) prepared on the same day and inter-day precision was calculated as the \%RSD of peak areas of three concentrations ( $n=6$ determinations per concentration per day) over three days $(n=18)$. Accuracy was determined as the average peak area for three concentrations $(n=6)$ as a percent of the value for their corresponding concentrations based on the linear regression calculation. The matrix effect of doxorubicin was investigated in six batches of each type of media with low and high concentrations undergoing the same centrifugation, drying, and reconstitution steps. The matrix factor $(\mathrm{MF})$ was calculated as $\mathrm{MF}=$ (analyte peak area of the matrix-matched calibration standard)/(analyte peak area of a pure standard sample) [22]. The variation of the matrix factor (relative standard deviation) was $<15 \%$.

\subsubsection{Limits of Detection and Quantification}

The peak area from the blank samples at the same retention time of the DXR was analyzed to determine the noise. The lower limit of detection (LLOQ) and lower limit of quantification (LLOQ) were based on the concentration at which the peak area of the drug was at least three times and ten times higher than the noise (blank samples) at that retention time, respectively.

\subsubsection{Stability of Samples}

Stability of the samples in each of the media were studied for 1 week at $4{ }^{\circ} \mathrm{C}$. These conditions were chosen based on the temperature and maximum storage time to which typical experimental samples are subjected. Results were calculated as a percent change. Percent change was calculated by the difference obtained in the peak area of the same sample on Day 1 and on Day 8, divided by the peak area of that sample on Day 1. 


\section{Results and Discussion}

\subsection{HPLC Method Development}

Due to the intrinsic fluorescence of doxorubicin, concentrations were analyzed using a fluorescence detector $\left(\lambda_{\mathrm{ex}}: 480 \mathrm{~nm} ; \lambda_{\mathrm{em}}: 550 \mathrm{~nm}\right)$. Samples were analyzed in both DMEM/F12 media and fetal perfusion media. Irrespective of the media used, the DXR peak was at a retention time of $6.0 \pm 0.1 \mathrm{~min}$ with no interfering peaks (Figures 1 and 2). In addition, low and consistent noise obtained following the sample treatment confirmed the reproducibility and absence of contamination from samples even after the solvent evaporation step.

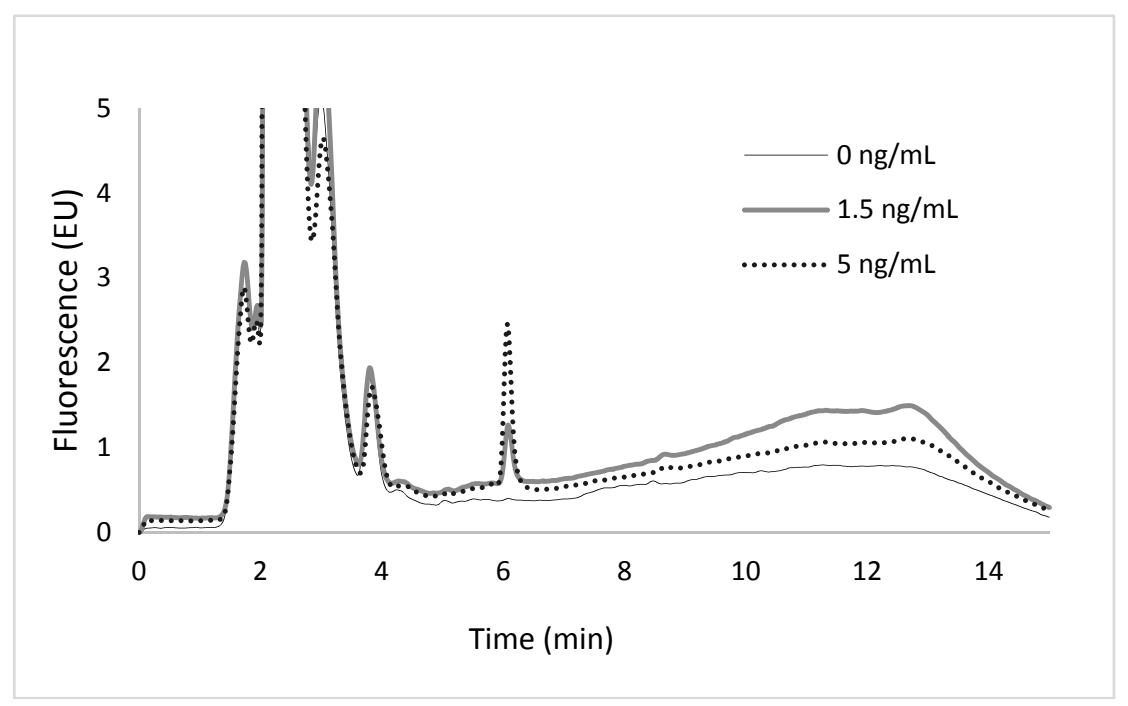

Figure 1. Chromatograms showing a peak for doxorubicin in DMEM/F12 medium analyzed with a fluorescence detector for a blank $(0 \mathrm{ng} / \mathrm{mL})$, a lower limit of detection $(1.5 \mathrm{ng} / \mathrm{mL})$, and a lower limit of quantification $(5 \mathrm{ng} / \mathrm{mL})$ at a retention time of $6.0 \pm 0.1 \mathrm{~min}$.

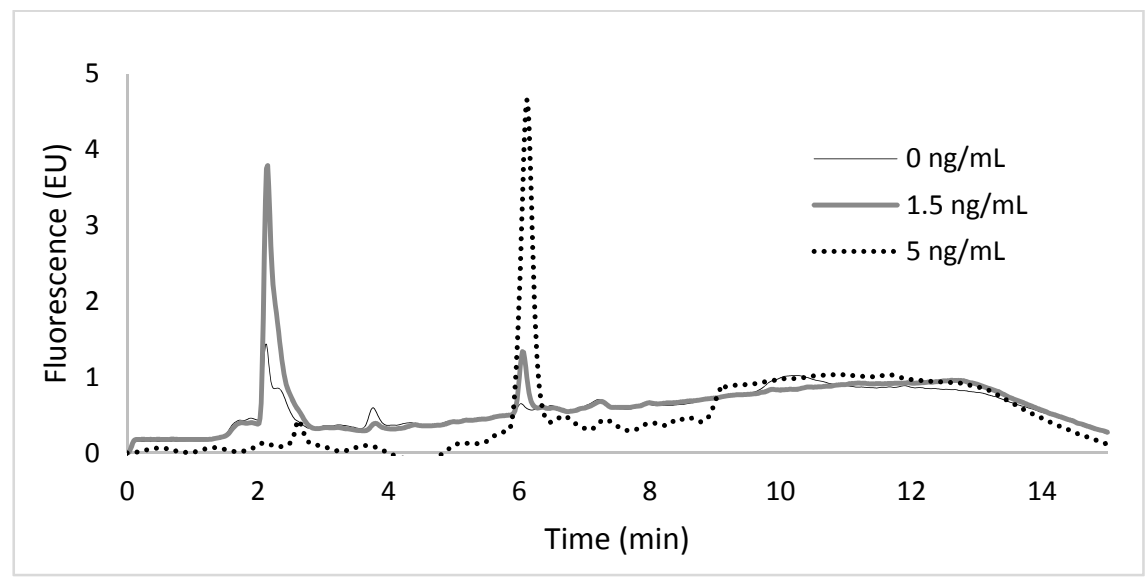

Figure 2. Chromatograms showing a peak for doxorubicin in fetal perfusion medium analyzed with a fluorescence detector for blank $(0 \mathrm{ng} / \mathrm{mL})$, lower limit of detection $(1.5 \mathrm{ng} / \mathrm{mL})$, and lower limit of quantification $(5 \mathrm{ng} / \mathrm{mL})$ samples at a retention time of $6.0 \pm 0.1 \mathrm{~min}$.

\subsection{Linearity, Precision, and Accuracy}

The relationship of peak area to concentration was found to be linear throughout the concentration range studied for both media. Using SigmaPlot, linear regressions were generated based on $1 / y$ 
weighting and the results of slope, intercept, and correlation coefficient are shown in Table 1. A correlation coefficient of 0.99 or greater was obtained for the concentration range $(1.5-15,000 \mathrm{ng} / \mathrm{mL})$ for all three days with both types of media. The data calculated for intra-day precision, inter-day precision, and accuracy are shown in Table 2. The intra-day precision and inter-day precision were found to be less than 15\% for all three studied concentrations in DMEM/F12 and placental perfusion media, which was within acceptable limits. Accuracy was also found to be between $90 \%$ and $110 \%$ for all the concentrations studied. As shown in Table 3, the matrix factor of doxorubicin is in the range of $97-113 \%$ with a variation $<11 \%$. These results indicate that no significant matrix effect was observed in either type of media.

Table 1. Linear regression characteristics.

\begin{tabular}{ccccccc}
\hline Regression Parameters & Day 1 & Day 2 & Day 3 & Average & Standard Deviation & RSD (\%) \\
\hline \multicolumn{7}{c}{ DMEM/F-12 } \\
\hline Intercept & 4191.9 & 2513.3 & 3749.7 & 3485.0 & 870.1 & 24.9 \\
Slope & $3.761 \times 10^{7}$ & $3.940 \times 10^{7}$ & $3.753 \times 10^{7}$ & $3.818 \times 10^{7}$ & $1.06 \times 10^{6}$ & 0.002 \\
$\boldsymbol{R}^{\mathbf{2}}$ & 0.9996 & 0.9988 & 0.9954 & 0.9979 & 0.2 \\
\hline \multicolumn{7}{c}{ Fetal M199 } \\
\hline Intercept & 10253.5 & 9697.6 & 10453.9 & 10135.0 & 391.9 \\
Slope & $4.592 \times 10^{7}$ & $4.341 \times 10^{7}$ & $4.228 \times 10^{7}$ & $4.387 \times 10^{7}$ & $1.86 \times 10^{6}$ \\
$\boldsymbol{R}^{2}$ & 0.9974 & 0.9966 & 0.9993 & 0.9978 & 0.001 \\
\hline
\end{tabular}

Table 2. Precision and accuracy.

\begin{tabular}{|c|c|c|c|c|c|}
\hline \multirow{2}{*}{ Concentration $(\mu \mathrm{g} / \mathrm{mL})$} & \multicolumn{3}{|c|}{ Intra-Day Precision (\%) } & \multirow{2}{*}{ Inter-Day Precision (\%) } & \multirow{2}{*}{ Accuracy (\%) } \\
\hline & Day 1 & Day 2 & Day 3 & & \\
\hline \multicolumn{6}{|c|}{ DMEM/F-12 } \\
\hline 0.05 & 5.7 & 1.2 & 1.9 & 7 & 96.4 \\
\hline 5 & 2.6 & 5.3 & 9.1 & 3.3 & 101.6 \\
\hline 10 & 2.7 & 10.3 & 6.4 & 1.2 & 100.1 \\
\hline \multicolumn{6}{|c|}{ Fetal M199 } \\
\hline 0.05 & 4.1 & 3.5 & 3.6 & 11.3 & 103.1 \\
\hline 5 & 2.8 & 2.8 & 3.4 & 0.9 & 100.2 \\
\hline 10 & 0.5 & 1.6 & 3.2 & 6.3 & 102.8 \\
\hline
\end{tabular}

Table 3. Matrix factor of doxorubicin in DMEM/F12 and fetal M199 media $(n=6)$.

\begin{tabular}{ccc}
\hline \multirow{2}{*}{ Measured Concentration $(\mu \mathrm{g} / \mathrm{mL})$} & \multicolumn{2}{c}{ Matrix Factor (\%) } \\
\cline { 2 - 3 } & DMEM/F12 & Fetal M199 \\
\hline 0.01 & $113.1 \pm 6.4$ & $101.1 \pm 10.8$ \\
10.0 & $109.7 \pm 7.0$ & $96.6 \pm 9.4$ \\
\hline
\end{tabular}

\subsection{Limits of Detection and Quantification}

Using the protein precipitation technique, the lower limit of detection (LLOD) was found to be $1.5 \mathrm{ng} / \mathrm{mL}$ in both types of media. This was of particular concern because the albumin concentration in perfusion media $(30 \mathrm{mg} / \mathrm{mL})$ is much higher than that in cell culture media $(22 \mathrm{mg} / \mathrm{mL})$, which could have led to differences in LLOD at low concentrations. Even though the precision at the LLOD was found to be poor due to background noise interference at this very low concentration, this analytical method still had a limit of quantification of $5 \mathrm{ng} / \mathrm{mL}$ in DMEM/F12 and placental perfusion media with acceptable accuracy and precision. This LLOQ is comparable to that of methods requiring liquid-liquid extraction [23]. 


\subsection{Sample Stability}

Doxorubicin was found to be stable for 1 week at $4{ }^{\circ} \mathrm{C}$ in DMEM/F12 as well as in placental perfusion media. Peak areas of doxorubicin in both types of media at all concentrations tested were comparable with minimal change following storage (Table 4). No additional peaks or alterations in retention time were observed. These results indicate that the storage conditions chosen are suitable for experimental samples.

Table 4. Stability of samples at $4{ }^{\circ} \mathrm{C}$ for 1 week.

\begin{tabular}{cccc}
\hline Nominal Concentration $(\mu \mathrm{g} / \mathrm{mL})$ & \multicolumn{4}{c}{ Measured Concentration $(\mu \mathrm{g} / \mathrm{mL})$} \\
\hline \multicolumn{5}{c}{ Day 1 } & Day 8 & $\%$ Change \\
\hline & In DMEM/F12 cell culture media \\
\hline 5 & 0.050 & 0.049 & $1.3 \%$ \\
10 & 5.02 & 4.44 & $11.5 \%$ \\
& 10.19 & 9.57 & $6.1 \%$ \\
\hline 0.05 & In fetal placental perfusion media \\
5 & 0.052 & 0.048 & $8.5 \%$ \\
10 & 4.80 & 4.45 & $7.2 \%$ \\
& 10.50 & 10.53 & $0.3 \%$ \\
\hline
\end{tabular}

\subsection{Transplacental Transfer of DXR across BeWo Cells and the Dually Perfused Human Placental Lobule}

The samples collected after the transport study and placental perfusion were analyzed using the developed HPLC method. Representative chromatograms are shown in Figure 3. It appears that the obtained chromatograms show DXR eluting at the same retention time, irrespective of whether the drug was studied using a BeWo cell monolayer or a placental lobule. Despite the fact that the placental lobule contains blood and other substances, the protein precipitation technique applied herein has successfully allowed the detection of DXR without any interference.

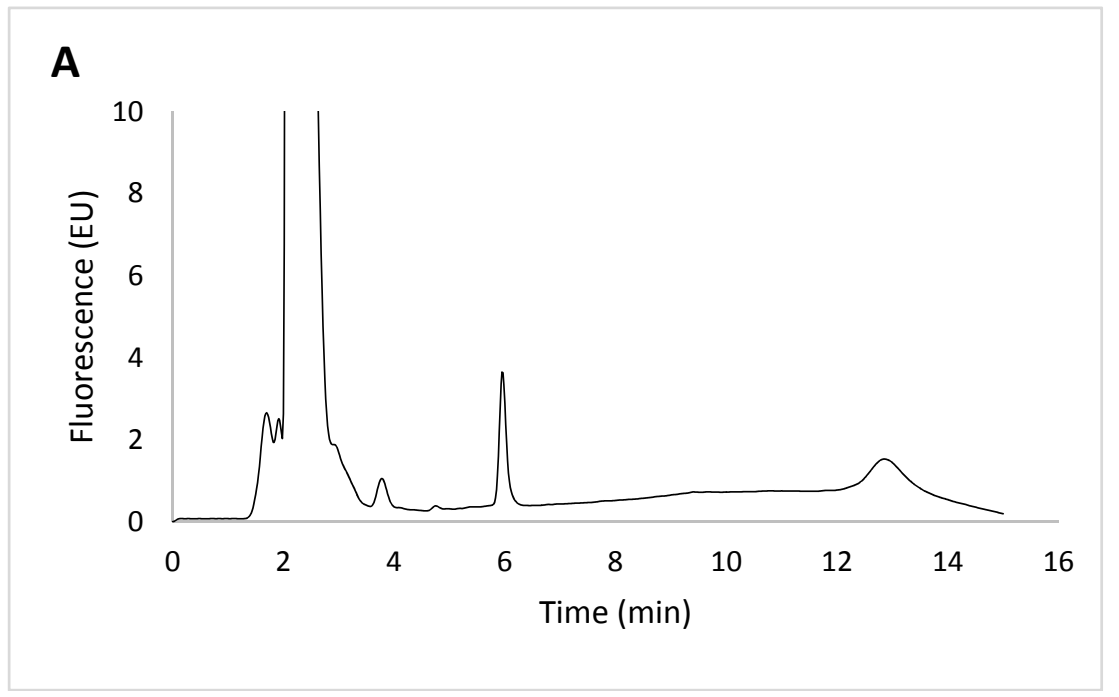

Figure 3. Cont. 


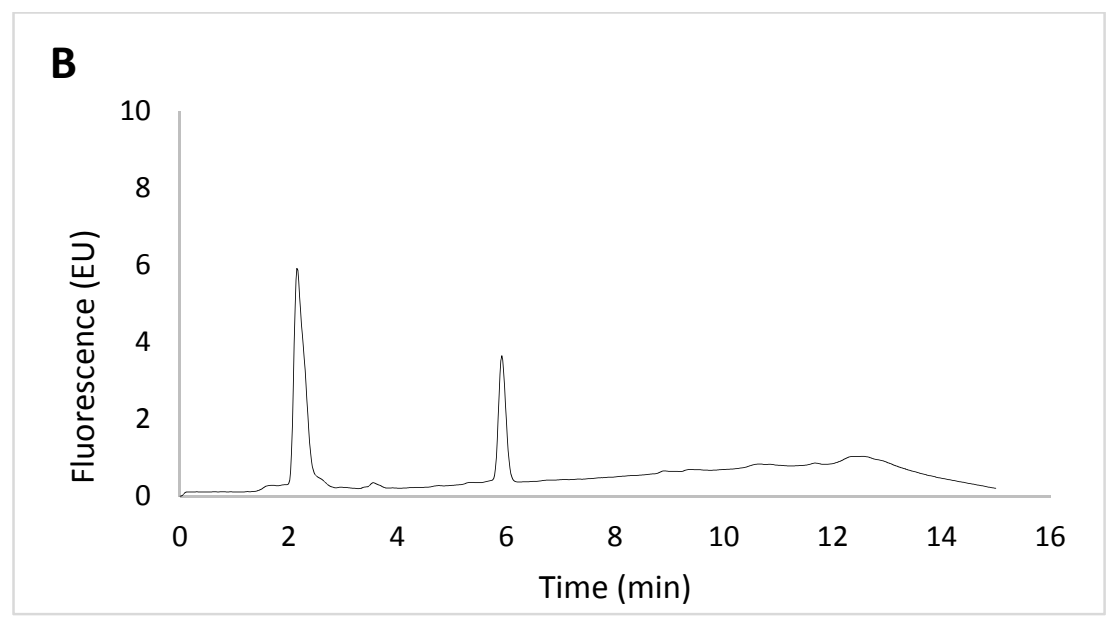

Figure 3. Chromatograms showing a peak for doxorubicin (retention time of $6 \mathrm{~min}$ ) from samples collected from a transport study in BeWo cells (A) and placental perfusion (B) analyzed with the developed HPLC method.

\section{Conclusions}

The analytical method developed in this study was found to be simple and sensitive in both types of media tested. Despite the high albumin concentration used in fetal perfusion media along with other components, the method was able to resolve, identify, and quantify DXR without substantial interference from matrix components. Excellent linearity, precision, and accuracy across all the concentrations studied were obtained using this technique. This method involving protein precipitation and fluorescence detection had lower limits of detection and quantification of $1.5 \mathrm{ng} / \mathrm{mL}$ and $5.0 \mathrm{ng} / \mathrm{mL}$, respectively, while bypassing the need for more expensive instrumentation such as LC/MS. Therefore, this method can be used further with great confidence to understand the transplacental transfer of doxorubicin across BeWo cells and in placental perfusion experiments.

Acknowledgments: This work was supported by the Eunice Kennedy Shriver National Institute of Child Health and Human Development (U54HD047891). The authors express gratitude to Xiaoming Wang for technical advice.

Author Contributions: M.S. designed the study, collected data, performed statistical analysis, and wrote the first draft of the manuscript. L.B., S.A., S.A.-E., M.M.Y., and M.F. collected data. E.R. assisted with statistical analysis and writing.

Conflicts of Interest: The authors declare no conflict of interest.

\section{References}

1. Daw, J.R.; Hanley, G.E.; Greyson, D.L.; Morgan, S.G. Prescription drug use during pregnancy in developed countries: A systematic review. Pharmacoepidemiol. Drug Saf. 2011, 20, 895-902. [CrossRef] [PubMed]

2. Loebstein, R.; Lalkin, A.; Koren, G. Pharmacokinetic changes during pregnancy and their clinical relevance. Clin. Pharmacokinet. 1997, 33, 328-343. [CrossRef] [PubMed]

3. Soininen, S.K.; Repo, J.K.; Karttunen, V.; Auriola, S.; Vähäkangas, K.H.; Ruponen, M. Human placental cell and tissue uptake of doxorubicin and its liposomal formulations. Toxicol. Lett. 2015, 239, 108-114. [CrossRef] [PubMed]

4. Speth, P.A.J.; van Hoesel, Q.G.C.M.; Haanen, C. Clinical Pharmacokinetics of Doxorubicin. Clin. Pharmacokinet. 1988, 15, 15-31. [CrossRef] [PubMed]

5. Gabizon, A.; Shmeeda, H.; Barenholz, Y. Pharmacokinetics of Pegylated Liposomal Doxorubicin. Clin. Pharmacokinet. 2003, 42, 419-436. [CrossRef] [PubMed]

6. Chiannilkulchai, N.; Ammoury, N.; Caillou, B.; Devissaguet, J.P.; Couvreur, P. Hepatic tissue distribution of doxorubicin-loaded nanoparticles after i.v. administration in reticulosarcoma M 5076 metastasis-bearing mice. Cancer Chemother. Pharmacol. 1990, 26, 122-126. [CrossRef] [PubMed] 
7. Cartwright, L.; Poulsen, M.; Nielsen, H.; Pojana, G.; Knudsen, L.E.; Saunders, M.; Rytting, E. In vitro placental model optimization for nanoparticle transport studies. Int. J. Nanomed. 2012, 7, 497-510.

8. Saunders, M. Transplacental transport of nanomaterials. Wiley Interdiscip. Rev. Nanomed. Nanobiotechnol. 2009, 1, 671-684. [CrossRef] [PubMed]

9. Alhareth, K.; Vauthier, C.; Gueutin, C.; Ponchel, G.; Moussa, F. HPLC quantification of doxorubicin in plasma and tissues of rats treated with doxorubicin loaded poly(alkylcyanoacrylate) nanoparticles. J. Chromatogr. B Anal. Technol. Biomed. Life Sci. 2012, 887-888, 128-132. [CrossRef] [PubMed]

10. Daeihamed, M.; Haeri, A.; Dadashzadeh, S. A Simple and Sensitive HPLC Method for Fluorescence Quantitation of Doxorubicin in Micro-volume Plasma: Applications to Pharmacokinetic Studies in Rats. Iran. J. Pharm. Res. IJPR 2015, 14, 33-42. [PubMed]

11. Beijnen, J.H.; Meenhorst, P.L.; Van Gijn, R.; Fromme, M.; Rosing, H.; Underberg, W.J.M. HPLC determination of doxorubicin, doxorubicinol and four aglycone metabolites in plasma of AIDS patients. J. Pharm. Biomed. Anal. 1991, 9, 995-1002. [CrossRef]

12. Lucas, A.T.; O'Neal, S.K.; Santos, C.M.; White, T.F.; Zamboni, W.C. A sensitive high performance liquid chromatography assay for the quantification of doxorubicin associated with DNA in tumor and tissues. J. Pharm. Biomed. Anal. 2016, 119, 122-129. [CrossRef] [PubMed]

13. Camaggi, C.M.; Comparsi, R.; Strocchi, E.; Testoni, F.; Pannuti, F. HPLC analysis of doxorubicin, epirubicin and fluorescent metabolites in biological fluids. Cancer Chemother. Pharmacol. 1988, 21, 216-220. [CrossRef] [PubMed]

14. Urva, S.R.; Shin, B.S.; Yang, V.C.; Balthasar, J.P. Sensitive high performance liquid chromatographic assay for assessment of doxorubicin pharmacokinetics in mouse plasma and tissues. J. Chromatogr. B 2009, 877, 837-841. [CrossRef] [PubMed]

15. Arnold, R.; Slack, J.; Straubinger, R. Quantification of doxorubicin and metabolites in rat plasma and small volume tissue samples by liquid chromatography/electrospray tandem mass spectroscopy. J. Chromatogr. B 2004, 808, 141-152. [CrossRef] [PubMed]

16. Niu, H.; Xu, M.; Li, S.; Chen, J.; Luo, J.; Zhao, X.; Gao, C.; Li, X. High-Performance Liquid Chromatography (HPLC) Quantification of Liposome-Delivered Doxorubicin in Arthritic Joints of Collagen-Induced Arthritis Rats. Med. Sci. Monit. Basic Res. 2017, 23, 150-158. [CrossRef] [PubMed]

17. Berveiller, P.; Vinot, C.; Mir, O.; Broutin, S.; Deroussent, A.; Seck, A.; Camps, S.; Paci, A.; Gil, S.; Tréluyer, J.M. Comparative transplacental transfer of taxanes using the human perfused cotyledon placental model. Am. J. Obstet. Gynecol. 2012, 207, 514.e1-514.e7. [CrossRef] [PubMed]

18. Nekhayeva, I.A.; Nanovskaya, T.N.; Pentel, P.R.; Keyler, D.E.; Hankins, G.D.; Ahmed, M.S. Effects of nicotine-specific antibodies, Nic311 and Nic-IgG, on the transfer of nicotine across the human placenta. Biochem. Pharmacol. 2005, 70, 1664-1672. [CrossRef] [PubMed]

19. Albekairi, N.A.; Al-Enazy, S.; Ali, S.; Rytting, E. Transport of digoxin-loaded polymeric nanoparticles across BeWo cells, an in vitro model of human placental trophoblast. Ther. Deliv. 2015, 6, 1325-1334. [CrossRef] [PubMed]

20. Earhart, A.; Patrikeeva, S.; Wang, X.; Abdelrahman, D.R.; Hankins, G.; Ahmed, M.; Nanovskaya, T. Transplacental transfer and metabolism of bupropion. J. Matern. Neonatal Med. 2009, 23, 1-10. [CrossRef] [PubMed]

21. ICH Guidlines. Guidances (Drugs)—Q2 (R1) Validation of Analytical Procedures: Text and Methodology. 2005. Available online: https: / www.fda.gov/Drugs/GuidanceComplianceRegulatoryInformation/Guidances / ucm265700.htm (accessed on 27 February 2017).

22. Clark, C.R.; Dowling, P.M.; Boison, J.O. Development and validation of a method for determination of tilmicosin residues in equine plasma and tissues using HPLC. J. Liq. Chromatogr. Relat. Technol. 2009, 32, 2839-2856. [CrossRef]

23. Van Calsteren, K.; Verbesselt, R.; Beijnen, J.; Devlieger, R.; De Catte, L.; Chai, D.C.; Van Bree, R.; Heyns, L.; de Hoon, J.; Amant, F. Transplacental transfer of anthracyclines, vinblastine, and 4-hydroxy-cyclophosphamide in a baboon model. Gynecol. Oncol. 2010, 119, 594-600. [CrossRef] [PubMed]

(C) 2018 by the authors. Licensee MDPI, Basel, Switzerland. This article is an open access article distributed under the terms and conditions of the Creative Commons Attribution (CC BY) license (http:/ / creativecommons.org/licenses/by/4.0/). 